\title{
An Empirical Analysis on the Development of Modern Service Industry and Its Countermeasures in Qingdao during Post-WTO Transitional Period
}

\author{
Wenxue Zhang (Corresponding author) \\ School of Business and Economics, Qingdao Technological University \\ No 2 of Middle Changjiang Street, Qingdao 266520, China \\ Tel: 86-532-8687-9006 E-mail: zhwx@qtech.edu.cn \\ Peng Liu \\ School of Business and Economics, Qingdao Technological University \\ No 2 of Middle Changjiang street, Qingdao 266520, China \\ Tel: 86-532-8687-9891Ｅ-mail: lpwater@126.com
}

The research is financed by the Education Department of Shandong province. No. J08WE16

\begin{abstract}
With the end of Post-WTO Transitional Period, Qingdao's modern services present a picture of unprecedented prosperity. But during the process of development, many sharp problems emerged and it needs to handle seriously. By an empirical analysis on influencing factors of modern services in Qingdao, existing problems are found out and corresponding countermeasures are put forward.
\end{abstract}

Keywords: Post-WTO Transitional Period, Qingdao's modern services, Influencing factors, Countermeasure

\section{The existing problems in the development of Qingdao's modern service industry}

1.1 Though a strong trend of development it may have, Qingdao's modern services, relatively speaking, have characteristics of small amount, low proportion, as well as slow development

The tertiary industry of Qingdao has got a fast development in recent years. Its added value amounts to half GDP of Qingdao. (See figure 1). The finance and insurance, tourism and other service industries form the main part of Qingdao's modern services, and their proportion in the tertiary industry increased year by year. But in the view of horizontal comparison domestically, the proportion of tertiary industry in GDP of Jinan, Shanghai and Beijing, is $50.1 \%, 60 \%$ and $72 \%$ respectively in the year of 2008 . If compared it internationally, the gap is wider. In 2008 , the average proportion of tertiary industry in GDP of the world is higher than $65 \%$. This proportion is more than $70 \%$ for most developed countries, nearly $40 \%$ for most developing countries, and nearly $60 \%$ for India.

Insert Figure 1 Here

1.2 The pulling effect of modern services haven't been fully played regionally, which largely influenced the economic development of Qingdao directly

Depending on the "Five district and one Port", the Qingdao Economic and Technological Development Zone in western Qingdao starts the strategy of "Port-FTZ interact", so as to build a major center of gathering, storaging, assembly, and distribution for domestic and international merchandises in northern China. The Qingdao New and Hi-Tech Development Zone and Qingdao Tourism\&Holiday Zone in the eastern Qingdao focus on the development of High-technology industry, the exhibition industry and the tourism and leisure industry. Shinan District has developed a regional economic development system including building, finance, software, tourism and cultural \& creative industry. In light of local conditions, the other areas of Qingdao, such as Shibei District, Sifang District, Licang District and Chengyang District, have also got a further development in the industry of retail, logistics, culture, and catering in recent years, which boom regional economy and satisfy consumption demands. But the pulling effect of these development hasn't been fully played, which largely influence the economic development of Qingdao.

From 2000 to 2008, the contribution rate of Qingdao's services to GDP growth increased from $41.6 \%$ to $45 \%$. But during the same period, this contribution rate of other cities in eastern China increased more strongly. From 2004 to 2008, this contribution rate of Shanghai increased from $46 \%$ to $60 \%$, and this contribution rate of Beijing increased from $61.9 \%$ to $72 \%$. Compared with similar cities in Guangdong, Jiangsu and Zhejiang 
province, Qingdao's services lag behind and the gap is getting larger.

1.3 Concerning the modern services in Qingdao, Finance, real estate and information software have got a fast growth, and meanwhile, tourism, logistics and marine service have got an outstanding development. However their service level is relatively low and their composite operation benefit is greatly restricted.

In 2008, the industry of finance and insurance of Qingdao got income of 17.35 billion Yuan, which accounts for $4 \%$ of Qingdao's GDP. The industry of real estate completed an income of 15.04 billion Yuan, and the industry of housing, catering and transportation completed an income of 90.07 billion Yuan. As for the tourism industry, it has become another pillar industry, and its income reached a new height of more than 50 billion Yuan. The application of information technology facilitated fast development of modern logistics. But their service level is relatively low, and their composite operation benefit is greatly restricted. The growth rate of labor productivity of Qingdao's services is far behind that of similar cities of Beijing, Shanghai, Guangdong, Jiangsu and Zhejiang. The added value per capita created by employees of service industry in Qingdao is only $60-70 \%$ of that of those similar cities.

\subsection{The overall speed of growth tends to slow down, and the lifting speed of industry structure slows down too.}

The overall speed of growth of Qingdao's modern services has slowed down since 1995. From table 1, we can see that the proportion of service industry to GDP in Qingdao increased from 20.8\% in 1995 to the peak value of $26 \%$ in 2003 , and then declined slowly, and then rebounded since 2006 to $23.7 \%$ in 2008 . The growth speed tends to slow down and so is the lifting speed of industry structure. From graph 2, we can see that proportion of Qingdao's service industry to its GDP has been promoted substantially since 1990 . But in recent years, the growth speed of service industry slowed down, so was the proportion of service industry to GDP. In 2005, the added value of service industry accounts for $41.6 \%$ of GDP. In 2008, this proportion rose to $45 \%$. Compared with similar cities of Guangdong, Jiangsu, Zhejiang, the modern industry of Qingdao falls behind and the gap is still very large.

Insert Table 1 Here

\section{An analysis on the factors that influence the development of Qingdao's modern service industry}

\subsection{A general analysis on the influencing factors}

2.1.1 Qingdao's modern service industry has a low level of development, slow growth rate and an unreasonable internal structure

Qingdao's modern service industry doesn't make a prominent performance in promoting the adjustment of economic structure and optimization of industrial structure. Firstly, the added value of Qingdao's modern service industry is small in overall scale, low in proportion, and unreasonable in view of internal structure. The proportion of its added value to GDP has lingered around 20\% in recent years. The proportion of technology intensive service industry and human capital intensive service industry is tending to be small. Secondly, Qingdao's producer service industry and consumer service industry, which offer intermediate demand service to modern production sectors, have an unreasonable structure and low efficiency. Thirdly, regarding the support system of modern manufacturing industry, Qingdao's modern service industry is in the situation of incomplete development with a lagging development to serve the manufacturing industry pre-production and post-production, and it can't meet the demand of the manufacturing industry in rapid growth.

2.1.2 The reform of administration system lags behind. Policy barriers to entry and many phenomena of monopoly still exist in modern service industry. Imperfection exists in policy-oriented mechanism.

Firstly, in many areas of Qingdao's modern service industry, the level of marketization is relatively very low, especially in the area of finance, telecommunication, railway and aviation. Such areas are in the situation of monopoly, regulation or limited operation due to the restriction of current systems and mechanisms. Secondly, Imperfection exists in policy-oriented mechanism. Although many encouraging policies have been produced in succession to promote the development of modern service industry, there are imperfections in policy system regarding the measures in implementation of such policies. These policies were basically drafted by a single industry and lacked the quality of wholeness and guidance.

\subsubsection{The proportion of service industry to GDP is hard to rise}

The growth model driven mainly by investment, the economic development pattern formed mainly by attracting foreign investment and carrying on international industrial transfer led to a strong development of manufacturing industry that limited the upside potential of service industry objectively. During the period of "the tenth five year plan" and "the eleventh five year plan", the investment of Qingdao in the second industry was much larger than 
that of service industry. Capital flow has great guiding impact on industry development. The proportion of service industry to GDP is hard to rise under such circumstance.

\subsubsection{Many factors limit the development of service industry}

Marketization, industrialization and internationalization haven't play fundamental role in resource allocation of service industry. The mechanism of determination of service price by market hasn't been established. The pattern of various economic sectors coexisting and developing together hasn't been formed. The service industry has an over reliance on government input and it has great difficulty in advancing by the way of industrialization. The low degree of marketization leads to services lack of motivation. The slow industrialization leads to it lack of energy. The low level of internationalization leads to it lack of competition. The lagging urbanization leads to it lack of demand.

2.1.5 The modern service industry is short of human resources, especially high-quality personnel.

The modern service industry is the industry of knowledge-intensive and talent-intensive. Most of service trades have the characteristics of high levels of human capital, the content of high-tech and high added-value. Their development demands high-quality personnel. A city's good development of services depends largely on its training, accumulation and utilization of professionals in modern service. Now, most of talented people in Qingdao are concentrating on oceanographic technology. Compared with many cities in China, Qingdao's high-level, inter-disciplinary, and international talent for modern service industry is very scarce. Such scarcity of talent has been a key factor restricting its development of modern service industry.

\subsection{An empirical analysis on factors influencing Qingdao's modern service industry}

With the data of Qingdao Statistical Yearbook, an econometric model for factors influencing the development of modern service industry from 1994 to 2008 is analyzed. The following visit variables are selected: (1) value added per capita in modern services industry (RJFW). The value-added of modern service sector equals value-added of the tertiary industry minus that of two traditional services sectors: Transportation, Storage, Post and telecommunication service sector, and the wholesale, retail trade and catering service sector. (2) Level of urbanization (CSHSP), which is represented by the proportion of urban population to national population. (3) Proportion of producer service industry to GDP (SCXFB). Due to the limitation of data acquisition, the value-added producer service industry is represented by the value-added of finance and insurance service sector. (4) Degree of industrialization (GYHCD), which is the proportion of value-added of the secondary industry to GDP. (5) Disposable income per capita. (RJSR)

The explained variable is RJFW. The explanatory variables are CSHSP, SCXFB, GYHCD and RJSR. Suppose there is linear relation between the explained variable and the explanatory variables in this model. Each variable is used and handled in logarithmic form. 15 years data of each variable between 1994 and 2008 is adopted to make data analysis and the data fitting result is showed in table 2 . Thus the basic form of the model can be obtained as the following:

$\log (\mathrm{RJFW})=13.71+7.11 \log (\mathrm{CSHSP})+0.29 \log (\mathrm{SCXFB})+2.29 \log (\mathrm{GYHCD})+2.73 \log (\mathrm{RJSR})$

From the regression results of table 2, we can see that all the explanatory variables have a significant effect on RJFW with a high goodness of fit of $99.14 \%$, and they can explain $98.79 \%$ part of RJFW variation. The statistics of the equation meet the requirement of significance. The coefficient of each variable shows that Level of urbanization has the largest influence on development of service sector, and next large influence comes from the disposable income per capita.

Insert Table 2 Here

By analyzing the above results, we can get the following conclusion:

Firstly, level of urbanization, disposable income per capita, degree of industrialization and modern producer service industry are major factors significantly influencing development of modern service industry. The significance of their influence decreases one by one.

Secondly, as a major part of modern service industry, the finance and insurance industry has comparatively little influence on modern service industry, which has much deviation with reality. Although the development of modern service industry benefits much from the healthy development of finance and real estate, it has comparatively little influence on Qingdao's modern service industry so far.

Thirdly, level of urbanization has significant influence on development of modern service industry. The level of urbanization in Qingdao is about 35\%, a very low level which restricts effective demand and supply of modern service. 
Fourthly, disposable income per capita has big contribution to and clear impact on service sector and it is a major factor influencing the development of modern service industry. Qingdao's disposable income per capita has been rising continuously and stably, especially for the urban residents. Such increase of disposable income per capita enhances people's ability to enjoy modern service.

\section{Strategic choice of Qingdao to develop modern service industry}

\section{1 clarifying the development strategy for Qingdao's modern service industry and the functions of government administration}

The government should establish a special leading group of modern service industry, and work out carefully "the Development Plan of Qingdao's Modern Service Industry". As for the important modern services in the plan, operative and practical guidance should be given in industry policy, tax preference, fiscal and financial assistance, price subsidy and land support. At the same time, the government should clarify the functions of government administration, truly setting enterprises and social organizations apart from government and also separating enterprises from social institutions. Remove and modify those rules not suitable for fast development of modern service. Break down the old closing system of self-service. Try to explore the way of industrialization of modern service industry.

3.2 Keep pushing the reform pace of Marketization, industrialization and socialization of Qingdao's modern service industry.

As for marketization, the government should promote marketization of resource allocation in modern service sector, relax regulations and restrictions, alter the industry organization structure of monopoly, and build a market order of fair competition. Market entry standards should be reduced. Market barriers should be eliminated. The quality of service should be improved. The efficiency of service should be increased. As for industrialization, many modern service enterprises should be cultivated with high credit, famous brand and international competitiveness. The guidance function of industry policy should be used to form an industrial development and an efficient and reasonable resource allocation. As for socialization, ancillary services which are not related to core competitiveness should be peeled off and self-service should be turned into social and professional service. During this process of transition, a target concept should be kept: high service efficiency and low service cost. The action of increasing "value discovery" of service economy artificially and incorrectly for purpose of seeking new economic growth should be forbidden. Such action may lead to self-inhibition of service economy.

\subsection{A systematic planning and design should be made on Qingdao's modern service industry.}

Accumulation areas of modern service with distinct characteristics should be built considering transition of urban functions, systematic structure, service network topology, and service industry chain and service information database. Centering on accumulation areas, function positioning and develop priority should be clarified, attraction of investments should be enhanced, and development of modern service should be accelerated.

\subsection{Great importance should be attached to professional training of modern service.}

The industry of modern service is highly knowledge-intensive and its value comes from high-quality professionals. So the key problem of talent insufficiency should be solved for Qingdao to develop modern service industry. Now talents of finance, software, information and consulting are very scarce, especially those of high-level compound talents who can deal with complicated difficulties, coordinations and cooperations. Emphasis should be put on the following works: (1) Preferential policies and high income should be adopted to attract high-level international talents in key areas of modern service sector. Overseas Chinese experts and students should be encouraged to homecoming and start business by various ways and methods. (2) The advantage of educational resources in Qingdao's universities and scientific research institutions should be fully used. Effective measures should be taken to strengthen the integration and cooperation of industry, education and research. Compound talents should be cultivated with great strength. (3) In order to satisfy the demand of modern service for human resource, existing personnel in modern service should be trained by experts and scholars and the employees of modern service should be sent to abroad to study further.

\section{References}

Mingshan Pan, Ankang Wang. (2009). Strategic choice of development of Shanghai's modern service industry. Shanghai City Development, 3,10-12

Guanhua Xu, Dongmei Liu, Qiyan Liu. (2009). Development trends and countermeasures of modern service 
industry. Study on Strategy and Decision-making, 3,248-255.

Qingdao statistical yearbook. (2008).

Note: this article is an periodical achievement of research project: Research on the internationalization of Qingdao's modern service industry during Post-WTO Transitional Period (Item number:J08WE16), one of the social and scientific program of universities funded by the Education Department of Shandong province

Table 1. the proportion of modern industry to GDP of Qingdao in major years

\begin{tabular}{|l|l|l|l|l|l|l|l|l|l|l|l|l|l|l|}
\hline year & 1995 & 1996 & 1997 & 1998 & 1999 & 2000 & 2001 & 2002 & 2003 & 2004 & 2005 & 2006 & 2007 & 2008 \\
\hline proportion & 20.8 & 19.9 & 22 & 21.6 & 21.6 & 25.1 & 26 & 25.9 & 26 & 22.8 & 20.1 & 21.1 & 22.2 & 23.7 \\
\hline
\end{tabular}

Source: according to the data from Qingdao Statistical Yearbook

Table 2. parameter estimation by the equation of linear regression

\begin{tabular}{|l|l|l|l|l|}
\hline \multirow{2}{*}{ model } & \multicolumn{2}{|l|}{ Unstandardized Coefficient } & \multirow{2}{*}{ T test value } & \multirow{2}{*}{ significance } \\
\cline { 2 - 3 } & B value & standard deviation & & 0.0144 \\
\hline Constant & 13.71146 & 4.637320 & 2.956763 & 0.0302 \\
\hline $\log ($ CSHSP $)$ & 7.111996 & 2.818099 & 2.523686 & 0.0018 \\
\hline $\log ($ SCXFB $)$ & 0.297305 & 0.070860 & 4.195681 & 0.0040 \\
\hline $\log ($ GYHCD $)$ & 2.285371 & 0.992427 & 2.302809 & 0.0000 \\
\hline $\log ($ RJSR $)$ & 2.727171 & 0.238319 & 7.247295 & \\
\hline
\end{tabular}

Remarks: $\mathrm{R} 2=0.9914$, adjustment $\mathrm{R} 2=0.9879, \mathrm{~F}=287.340, \mathrm{D}-\mathrm{W}=2.071$

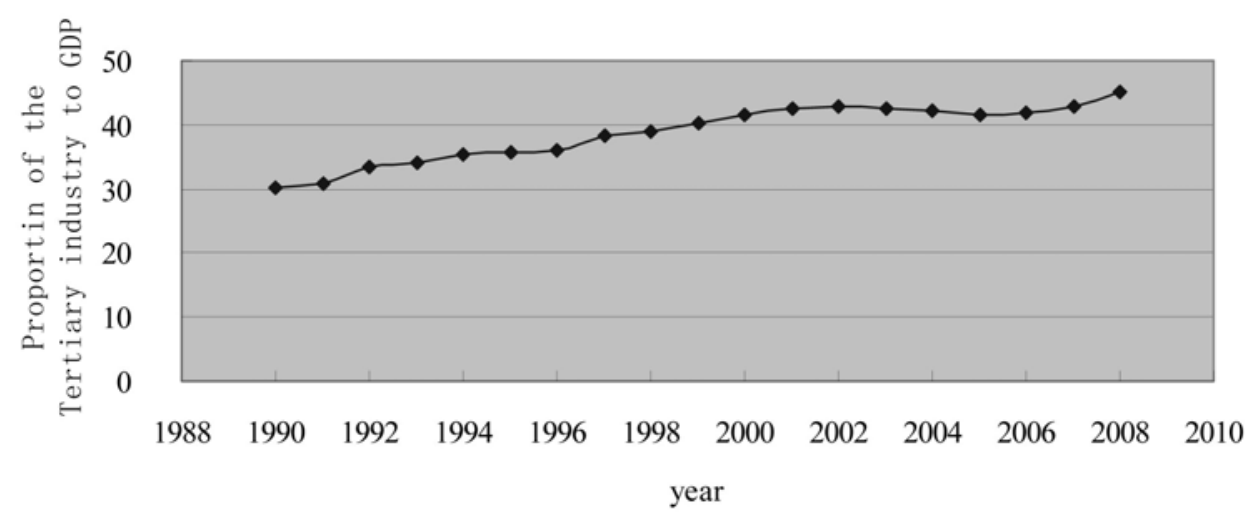

Figure 1. The proportion of added value of tertiary industry to GDP of Qingdao in major years 